\title{
Expression and regulatory effects of microRNA-182 in osteosarcoma cells: A pilot study
}

\author{
DONG-LIN BIAN ${ }^{1}$, XUE-MEI WANG ${ }^{1}$, KUN HUANG $^{1}$, QI-XI ZHAI ${ }^{1}$, GUI-BO YU ${ }^{2}$ and CHENG-HUA WU ${ }^{3}$ \\ ${ }^{1}$ Department of Ultrasound; ${ }^{2}$ Key Laboratory of Diagnosis and Interventional Therapy of Liaoning Province; \\ ${ }^{3}$ Department of Radiology, The First Affiliated Hospital of China Medical University, Shenyang, Liaoning 110001, P.R. China
}

Received January 19, 2015; Accepted February 19, 2016

DOI: $10.3892 / \mathrm{ol} .2016 .4375$

\begin{abstract}
The aim of the present study was to evaluate the expression level of microRNA-182 (miRNA-182) in human osteosarcoma (OS) MG-63 cells and OS tissues, and to elucidate the effect of miRNA-182 on the biological activity of tumors. In the present study, the expression of miRNA-182 in human OS MG-63 cells, OS tissues and normal osteoblast hFOB1.19 cells was determined using quantitative polymerase chain reaction. Subsequently, a miRNA-182 mimic and inhibitor were utilized to regulate the expression level of this miRNA in MG-63 cells. Cell viability and proliferation were examined using cell counting kit-8 assays, and cell apoptosis was detected by flow cytometry. Cell invasion and migration assays were performed using Transwell chambers to analyze the biological functions of miRNA-182 in vitro. The present study demonstrated that the expression level of miRNA-182 in MG-63 cells and OS tissues was significantly increased compared with the hFOB1.19 cell line $(\mathrm{P}<0.05)$. The present study successfully performed cell transfections of miRNA-182 inhibitor and miRNA-182 mimic into MG-63 cells and achieved the desired transfection efficiency. The present study confirmed that upregulation of miRNA-182 promotes cell apoptosis and inhibits cell viability, proliferation, invasion and migration. The present findings additionally demonstrated that miRNA-182 is a tumor suppressor gene in OS. Therefore, regulating the expression of miRNA-182 may affect the biological behavior of OS cells, which suggests a potential role for miRNA-182 in molecular therapy for malignant tumors.
\end{abstract}

\section{Introduction}

Cancer, including osteosarcoma (OS), is becoming an increasingly common disease and is characterized by uncontrolled

Correspondence to: Dr Xue-Mei Wang, Department of Ultrasound, The First Affiliated Hospital of China Medical University, 155 Nanjing North Street, Heping, Shenyang, Liaoning 110001, P.R. China

E-mail: 758839160@qq.com

Key words: osteosarcoma, microRNA-182, biological behaviors of neoplasms, gene expression growth (1). OS is the most commonly observed primary malignant bone tumor with a high morbidity in adolescents and young adults, and it primarily originates from mesenchymal tissue (2). OS is additionally the third most common cancer in childhood (3). Annually, 5.6 out of 1 million children $<15$ years old suffer from OS (4). With comprehensive treatment, the 5-year survival rate has increased to $60-70 \%$ (5); however, although the therapeutic management has been improved, metastasis eventually occurs in $\sim 80 \%$ of patients, and the lung is typically the most susceptible organ (6). The prognosis and curative effects of OS are closely associated with metastasis, and the majority of clinicians agree that early diagnosis is key to successful treatment (7).

MicroRNAs (miRNAs) belong to a family of small non-coding RNAs that have been identified in plants and animals, which are typically 19-24 nucleotides in length and function in transcriptional and post-transcriptional processes (8-10). The human genome may encode $>1,000$ miRNAs (11), which exist in a large number of human cells. miRNAs are generated from their own genes or introns, and are synthesized in the nucleus and cytosol. Generally, the formation of mature miRNAs is a complex process that requires the aid of a variety of biological molecules, including RNA polymerase II/III, Drosha, Pasha, exportin-5 and Dicer (12-16). However, only the end products of this process have biological activity and execute biological functions (17). It has been demonstrated that miRNAs regulate the expression of their target messenger (m)RNAs primarily by binding the mRNA 3' untranslated region (18-20). Furthermore, a miRNA may target multiple mRNA targets, and a target mRNA may be targeted by various miRNAs, which suggests that these regulatory RNAs exert complex, post-transcriptional control of gene expression $(21,22)$. miRNAs have enormous potential to regulate various crucial biological processes, including the differentiation, progression, proliferation, apoptosis, metastasis and invasion of tumor cells (23-26).

With improvements in medicine, increased knowledge and technology advancement, the association between miRNAs and cancer is being gradually revealed (27). As miRNAs are known to be implicated in the functioning of eukaryotic cells, consequently the dysregulation of miRNAs has been associated with various diseases (28). The first miRNAs identified to be involved in disease were miRNA-15 and miRNA-16, which were observed to be closely associated with chronic 
lymphocytic leukemia by Calin et al (29) in 2002. As an important member of the miRNA family, miRNA-182 is vital in tumor development. Studies have revealed that miRNA-182 functions as an oncogene or cancer suppressor gene in various tumors, including triple-negative breast cancer (30), gastric adenocarcinoma (31) and colon cancer (32); however, it remains to be elucidated whether miRNA-182 has similar functions in OS. Therefore, examining the expression level of miRNA-182 in normal osteoblast hFOB1.19 cells, as well as human OS MG-63 cells and OS tissues, was the primary aim of the present study. In addition, the present study was interested in controlling the expression level of miRNA-182 in MG-63 cells and subsequently investigating the biological activity of those cells.

\section{Materials and methods}

Cell lines and tissue specimens. The control cell line hFOB1.19 and 9 clinical specimens were obtained from the Department of Orthopedics of the First Hospital of China Medical University (Shenyang, China). hFOB1.19 is an established cell line that has been described in the literature (33). The 9 participants in the present study ranged in age between 11 months and 16 years. During surgery, a $2 \times 2-\mathrm{cm}$ section of each tumor was removed following excision of the tumor by the surgeon, and each specimen was subsequently transported on ice and preserved in liquid nitrogen until required. The human OS MG-63 cell line was purchased from the Culture Preservation Commission Cell Bank of the Chinese Academy of Sciences (Shanghai, China). The cell lines were cultured in Dulbecco's modified Eagle's medium (DMEM; Thermo Fisher Scientific, Inc., Waltham, MA, USA) containing $10 \%$ fetal bovine serum (FBS; Thermo Fisher Scientific, Inc.) at $37^{\circ} \mathrm{C}$ in a humidified atmosphere of $5 \% \mathrm{CO}_{2}$. In total, 9 patients were enrolled in the present study, and none of the patients had a history of chemotherapy, radiotherapy or other treatment prior to surgery. Furthermore, none of the patients had metastasis, as confirmed with ultrasound, computed tomography (CT), magnetic resonance imaging, and positron emission tomography-CT. All specimens were used only for miRNA extraction. Written informed consent was obtained from the parents or guardians of the patients prior to surgery. The present study was approved by the First Affiliated Hospital of China Medical University Medical Research Ethics Committee (Shenyang, China).

miRNA extraction. miRNA was isolated using RNAiso Plus (Takara Biotechnology Co., Ltd., Dalian, China) according to the manufacturer's protocol. Briefly, $1 \times 10^{4}-10^{6}$ cultured cells and 50-200 mg of tissue were collected and washed twice in phosphate-buffered saline (PBS; ZSGB-Bio Co., Ltd., Beijing, China) at $4^{\circ} \mathrm{C}$, and subsequently $1 \mathrm{ml}$ of RNAiso was added per $50-200 \mathrm{mg}$ or $1 \times 10^{4}-10^{6}$ cells. Following $5 \mathrm{~min}$ of incubation, $200 \mu 1$ chloroform (Tianjin Bodi Chemical Co., Ltd., Tianjin, China) was added, and the cells were agitated for $15 \mathrm{sec}$. Following an additional 5 min of incubation at room temperature, the mixture was centrifuged [Allegra X-30R; Beckman Coulter Commercial Enterprise (China) Co., Ltd., Shanghai, China] for $15 \mathrm{~min}$ at $12,000 \mathrm{x} \mathrm{g}$ at $4^{\circ} \mathrm{C}$. In total, $\sim 400 \mu \mathrm{l}$ of the aqueous phase was recovered and transferred to a fresh tube, to which $400 \mu \mathrm{l}$ isopropyl alcohol (Tianjin Bodi Chemical Co., Ltd.) was added, and the mixture was incubated for $10 \mathrm{~min}$. Subsequently, the mixture was centrifuged [Allegra X-30R; Beckman Coulter Commercial Enterprise (China) Co., Ltd.] for $10 \mathrm{~min}$ at $12,000 \mathrm{x} \mathrm{g}$ at $4^{\circ} \mathrm{C}$. Following centrifugation, $1 \mathrm{ml}$ $100 \%$ ethanol (Tianjin Bodi Chemical Co., Ltd.) was added to wash the precipitate three times. Finally, the precipitate was dried at room temperature and dissolved in $20 \mu \mathrm{l}$ RNAse-free $\mathrm{dH}_{2} \mathrm{O}$ (Takara Biotechnology Co., Ltd.). Immediately, the concentrations of the isolated miRNA samples were determined using a microplate reader (Multiskan ${ }^{\mathrm{TM}}$ GO; Thermo Fisher Scientific, Inc.).

Reverse transcription $(R T)$. The extracted miRNAs underwent RT to complementary (c)DNA using the PrimeScript RT Reagent kit (Takara Biotechnology Co., Ltd.) according to the manufacturer's protocol with minor modifications in the cycling conditions. The RT reaction volume was $10 \mu \mathrm{l}$, and the mixture contained $2 \mu \mathrm{l} 5 \mathrm{X}$ PrimeScript Buffer, $0.5 \mu \mathrm{l}$ PrimeScript RT Enzyme Mix I, $500 \mathrm{ng}$ extracted RNA and $0.5 \mu \mathrm{l}$ specific miRNA primer $(2 \mu \mathrm{M})$. The primers were obtained from GenScript Co., Ltd (Nanjing, China) and the sequences were as follows: miR-182-RT, 5'-GTCGTATCCAGTGCA GGGTCCGAGGTGCACTGGATACGACAGTGTGA-3'; U6-RT, 5'-GTCGTATCCAGTGCAGGGTCCGAGGTATTC GCACTGGATACGACAAAATATGGAAC-3'. U6 served as the internal reference gene. Finally, $10 \mu \mathrm{l}$ RNase-free $\mathrm{dH}_{2} \mathrm{O}$ was added to the mixture. The reaction conditions for reverse transcription were as follows: $42^{\circ} \mathrm{C}$ for $15 \mathrm{~min}, 85^{\circ} \mathrm{C}$ for $5 \mathrm{sec}$ and $4^{\circ} \mathrm{C}$ for $60 \mathrm{~min}$. The PCR apparatus (Dice ${ }^{\circledR}$ Gradient TP600) was purchased from Takara Biotechnology Co., Ltd. The cDNA was stored at $-20^{\circ} \mathrm{C}$ until required.

Identification of miRNA-182 expression in MG-63 cells and tissue specimens by quantitative PCR ( $P$ PCR). The expression of mature miRNA-182 was detected using the $\mathrm{SYBR}^{\circledR}$ Premix Ex Taq ${ }^{\mathrm{TM}}$ II kit (Takara Biotechnology Co., Ltd.), with $\mathrm{U} 6$ as the internal reference gene. The reaction volume was $20 \mu 1$, and the mixture contained $10 \mu \mathrm{l} \mathrm{SYBR}{ }^{\circledR}$ Premix Ex Taq, $2 \mu \mathrm{l}$ cDNA, $0.4 \mu \mathrm{l}(10 \mu \mathrm{M})$ miRNA-182 forward primer and miRNA-182 reverse primer or $0.4 \mu \mathrm{l}(10 \mu \mathrm{M}) \mathrm{U} 6$ forward primer and U6 reverse primer, and $7.2 \mu \mathrm{d}_{2} \mathrm{O}$. The primers were as follows: miRNA-182, forward 5'-TGCGGT TTGGCAATGGTAGAAC-3' and reverse, 5'-CCAGTGCAG GGTCCGAGGT-3'; U6, forward 5'-GCTTCGGCAGCACAT ATACTAAAAT-3' and reverse 5'-CGCTTCACGAATTTG CGTGTCAT-3'. The PCR amplification conditions were as follows: $95^{\circ} \mathrm{C}$ for $30 \mathrm{sec}$ and 40 cycles of $95^{\circ} \mathrm{C}$ for $5 \mathrm{sec}, 60^{\circ} \mathrm{C}$ for $20 \mathrm{sec}, 95^{\circ} \mathrm{C}$ for $5 \mathrm{sec}$ and $65^{\circ} \mathrm{C}$ for $15 \mathrm{sec}$. Three replicates were performed for each reaction. The qPCR instrument (LightCycler ${ }^{\circledR} 480$ II) was purchased from Roche Diagnostics, $\mathrm{GmbH}$ (Mannheim, Germany). The cycle threshold $(\mathrm{Cq})$ value of the specimens in each reaction tube was recorded, and the experimental data were analyzed using the qPCR relative quantification method (34): $2^{-\Delta \Delta \mathrm{Cq}}$ represented the fold change in the expression level of miRNA-182 in MG-63 cells or OS tissues compared with normal osteoblast hFOB1.19 cells.

Cell transfection and analysis of the expression level of miRNA-182 in MG-63 cells. Shortly prior to transfection, 
MG-63 cells were seeded into 6-well plates (BD Biosciences, Franklin Lakes, NJ, USA) at a concentration of 5-6x10 cells $/ \mathrm{ml}$ in $2 \mathrm{ml}$ per well of DMEM containing 10\% FBS. In total, 4-6 h prior to transfection, the cells were incubated in DMEM containing $10 \% \mathrm{FBS}$ at $37^{\circ} \mathrm{C}$ in a humidified atmosphere of $5 \%$ $\mathrm{CO}_{2}$. Subsequent to the cells adhering to the wells for $6-8 \mathrm{~h}$, the culture medium was aspirated from each well. Following aspiration, transfection complexes were formed by mixing $250 \mu \mathrm{l}$ culture medium without FBS, $10 \mu \mathrm{l} \mathrm{HiPerFect}{ }^{\circledR}$ Transfection Reagent (Qiagen, Inc., Valencia, CA, USA) and $10 \mu \mathrm{l}$ miRNA-182-5p inhibitor (100 nM; catalog no., miR200002591-5; Guangzhou RiboBio Co., Ltd., Guangzhou, China) or $8 \mu \mathrm{l}$ miRNA-182-5p mimic (80 nM; catalog no., miR10000259-1-5; Guangzhou RiboBio Co., Ltd.). The mixtures were incubated for 5-10 min at room temperature. Subsequently, the mixtures were added dropwise to the cells, and the plates were gently swirled to ensure uniform distribution of the transfection complexes. Non-transfected (MG-63 cells without transfection), negative (catalog no., miR02101-1-5; Guangzhou RiboBio Co., Ltd.) and fluorescence (catalog no., siN05815122149-1-5; Guangzhou RiboBio Co., Ltd.) controls were performed at the same time. Three duplicate wells were set up for each reaction. The cells were placed in an incubator at $37^{\circ} \mathrm{C}$ with $5 \% \mathrm{CO}_{2}$ for 24 h. RNAiso for Small RNA (Takara Biotechnology Co., Ltd.) was utilized to extract the RNA from each group of cells, and RT-qPCR was performed to detect the expression level of miRNA-182 in each group of MG-63 cells.

Cell viability and proliferation determined by cell counting kit-8 (CCK-8) assays. MG-63 cells that had undergone transfection were used in this assay. A total of $24 \mathrm{~h}$ subsequent to transfection, cells were treated with trypsin (Biosharp, Hefei, China) and counted using a cell counting plate. Subsequently, the cells were plated in 96-well plates (BD Biosciences) at a concentration of $5 \times 10^{4}$ cells $/ \mathrm{ml}$ in $100 \mu \mathrm{l}$ per well of DMEM with $10 \% \mathrm{FBS}$, and the plates were incubated at $37^{\circ} \mathrm{C}$ with $5 \% \mathrm{CO}_{2}$. The culture medium was replaced every $48 \mathrm{~h}$. Subsequent to 24, 48, 72 and 96 h, $10 \mu$ l CCK-8 (Dojindo Molecular Technologies, Inc., Kumamoto, Japan) was added to each well, and the plates were incubated for $4 \mathrm{~h}$ at $37^{\circ} \mathrm{C}$ with $5 \% \mathrm{CO}_{2}$. Subsequently, the optical density (OD) values at $450 \mathrm{~nm}$ were measured with a microplate reader (Multiskan ${ }^{\mathrm{TM}}$ GO), and a standard curve was constructed using 2-fold serial dilutions, thereby forming a cell concentration gradient. Each experimental group contained five duplicated wells, and the experiment was repeated three times.

Cell apoptosis determined using flow cytometry. Transfection of the miRNA-182 inhibitor, mimic and negative control was performed using HiPerFect Transfection Reagent according to the manufacturer's protocol. A total of $24 \mathrm{~h}$ subsequent to transfection, the culture medium was aspirated and the transfected cells were washed twice with PBS, treated with trypsin and centrifuged at $878 \times \mathrm{g}$ for $5 \mathrm{~min}$ (TDZ5-WS; Shanghai Xiangyi Centrifuge Instrument Co., Ltd., Shanghai, China). Subsequently, the precipitates were washed 2-3 times with PBS and centrifuged at $878 \times \mathrm{g}$ for $5 \mathrm{~min}$. A total of $200 \mu \mathrm{l}$ binding buffer (NeoBioscience, Shenzhen, China) was added to each tube of cells, and the mixtures were transferred into $1.5 \mathrm{ml}$ Eppendorf tubes (Eppendorf, Hamburg, Germany).
Subsequently, $5 \mu$ l Annexin V-fluorescein isothiocyanate (FITC; NeoBioscience) was immediately added to each tube, and the tubes were incubated at room temperature for $5 \mathrm{~min}$. Next, $10 \mu \mathrm{l}$ propidium iodide (PI; NeoBioscience) was added to each tube, and the tubes were incubated at room temperature for $10 \mathrm{~min}$. Finally, $300 \mu \mathrm{l}$ binding buffer was added to the tubes and the cells were analyzed using flow cytometry (BD FACSCalibur ${ }^{\text {TM }}$; BD Biosciences). The BD FACSCalibur was equipped with a dual laser (488 and $635 \mathrm{~nm}$ ) and CellQuest version 3.0 software (BD Biosciences). The analysis speed was $1 \times 10^{4}$ cells $/ \mathrm{sec}$.

Cell invasion and migration analyzed using Transwell invasion chambers. Transfection of the miRNA-182 inhibitor, mimic and negative control was performed using HiPerFect Transfection Reagent according to the manufacturer's protocol. A total of $24 \mathrm{~h}$ subsequent to transfection, $100 \mu \mathrm{l}$ diluted Matrigel (BD Biosciences; 1:2 dilution, Matrigel:DMEM) was added to a $8.0 \mu \mathrm{m}$ pore size Transwell chamber (12/24 well chamber; Corning Incorporated, Corning, NY, USA) and incubated for $4-5 \mathrm{~h}$ at $37^{\circ} \mathrm{C}$ with $5 \% \mathrm{CO}_{2}$. Following solidification of the Matrigel, the cells were dissociated with trypsin and resuspended in $1 \mathrm{ml}$ DMEM containing 8\% FBS. In total, $600 \mu \mathrm{l}$ DMEM containing $15 \%$ FBS was added to the lower chamber, and $200 \mu \mathrm{l}\left(4-6 \times 10^{5}\right.$ cells $\left./ \mathrm{ml}\right)$ of the cell suspension was seeded in the upper chamber of the Transwell apparatus. The experimental procedures for the migration assays were the same for invasion assays, except that Matrigel was not used. Cell invasion was observed $24 \mathrm{~h}$ later, and migration was observed $5 \mathrm{~h}$ later. Specifically, the cells were stained with hematoxylin (Wanlei Biotechnology Co., Ltd., Shenyang, China), and the number of cells considered to be invasive, or those that migrated through the polycarbonate membrane of the Transwell chamber, were counted under a microscope (Eclipse 80i; Nikon Corporation, Tokyo, Japan; magnification, x200). Ten fields were randomly observed.

Statistical analyses. GraphPad Prism 5 software (GraphPad Software, Inc., La Jolla, CA, USA) was used to statistically analyze the experimental data. Student's $t$ test was applied to compare two groups, and analysis of variance was applied to compare two or more sets of data followed by Student's $t$ test for post hoc analysis. Data is presented as the mean \pm standard deviation. $\mathrm{P}<0.05$ indicated a statistically significant difference.

\section{Results}

Relative expression level of miRNA-182 in MG-63 cells and tissue specimens. Using RT-qPCR, the present study demonstrated that the expression level of miRNA-182 in MG-63 cells $(0.73 \pm 0.09)$ and OS tissues $(0.72 \pm 0.09)$ was significantly reduced compared with the control hFOB1.19 cell line $(1.00 \pm 0.00)$ (Fig. 1). The OS tissue comprised 9 patient specimens, and the basic patient characteristics are presented in Table I. All specimens had a low expression of miRNA-182 in comparison to the hFOB1.9 control cells. Finally, the statistical mean of the expression level of miRNA-182 in the 9 patients was calculated $(0.72 \pm 0.09)$.

Relative expression level of miRNA-182 in MG-63 cells following transfection. A miRNA-182 inhibitor, mimic and 
Table I. Basic characteristics of 9 patients with osteosarcoma.

\begin{tabular}{lrrrlr}
\hline Patient & Gender & Age & Number of lesions & \multicolumn{1}{c}{ Lesion site } & Treatment \\
\hline 1 & M & $12 \mathrm{y}$ & 1 & Terminal femur & None \\
2 & $\mathrm{~F}$ & $8 \mathrm{y}$ & 1 & Proximal tibia & None \\
3 & $\mathrm{M}$ & $11 \mathrm{~m}$ & 1 & Tibia metaphyses & None \\
4 & $\mathrm{M}$ & $1 \mathrm{y}$ & 1 & Proximal tibia & None \\
5 & $\mathrm{M}$ & $16 \mathrm{y}$ & 1 & Femur metaphyses & None \\
6 & $\mathrm{M}$ & $13 \mathrm{y}$ & 1 & Tibia metaphyses & None \\
7 & $\mathrm{M}$ & $15 \mathrm{y}$ & 1 & Proximal tibia & None \\
8 & $\mathrm{~F}$ & $1 \mathrm{y}$ & Femur metaphyses & None \\
9 & $\mathrm{~F}$ & $10 \mathrm{y}$ & & Terminal femur & None \\
\hline
\end{tabular}

M, male; F, female; y, years; m, months.

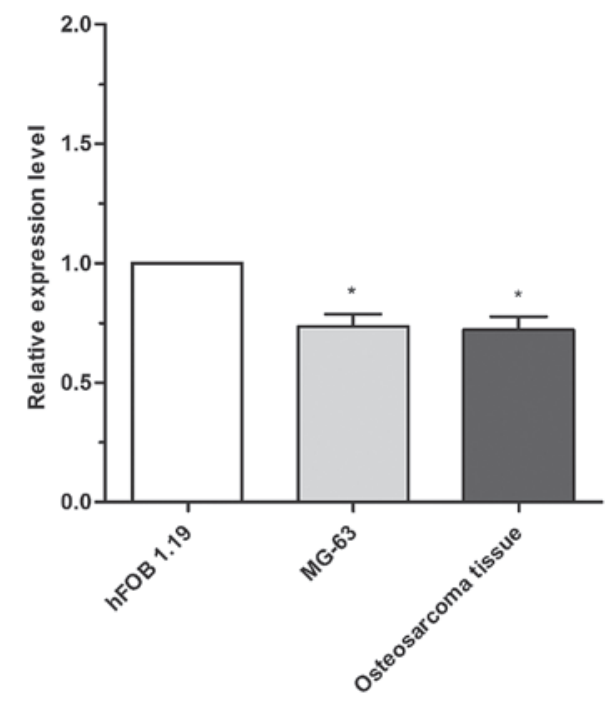

Figure 1. Relative expression of miRNA-182 in human OS MG-63 cells, OS tissues and control hFOB1.19 cell line. The expression level of miRNA-182 in MG-63 cells and OS tissues was significantly reduced compared with the control cell line. Experiments were repeated three times. Data are presented as the mean \pm standard deviation. " $\mathrm{P}<0.05$ vs. control cell line. miRNA, microRNA; OS, osteosarcoma.

negative control were transfected into MG-63 cells. The fluorescence control group confirmed that the transfection was efficient (Fig. 2). Using RT-qPCR, the present study identified that the expression levels of miRNA-182 in the miRNA-182 inhibitor transfection group $(0.63 \pm 0.12)$ were significantly decreased compared with the expression levels in the non-transfected control MG-63 cells $(1.87 \pm 0.08)$ and negative control groups $(1.89 \pm 0.11)$. Furthermore, the expression level of miRNA-182 in the group transfected with miRNA-182 mimic $(2.81 \pm 0.15)$ was significantly increased compared with the control groups (Fig. 3).

Effects of miR-182 on cell viability and proliferation. Using a CCK-8 assay, it was demonstrated that the cell viability of cells transfected with the miRNA-182 inhibitor was increased compared with the non-transfected control and negative control transfected cell groups. In addition, the viability of

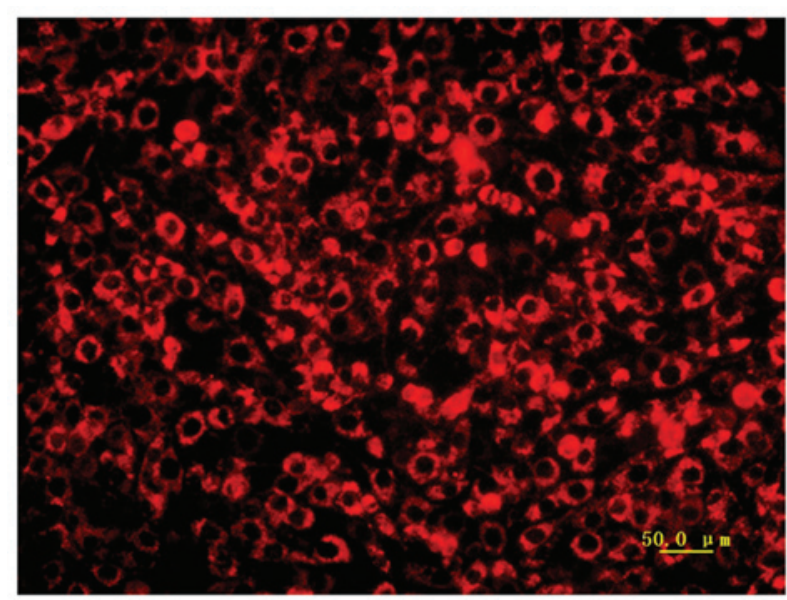

Figure 2. Transfection efficiency. Fluorescence microscopy of human osteosarcoma MG-63 cells transfected with the fluorescence control demonstrated that transfection efficiency was high (magnification, x100).

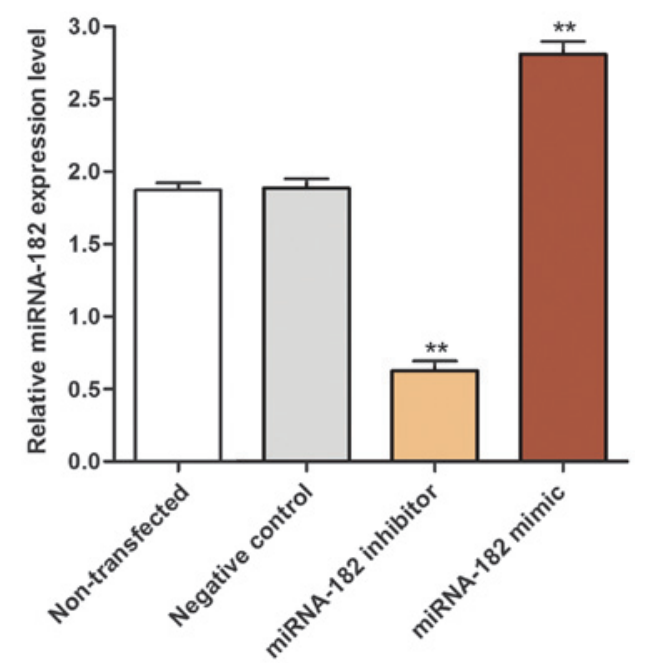

Figure 3. Effects on miRNA-182 expression following transfection of human osteosarcoma MG-63 cells with a miRNA-182 inhibitor or mimic. The expression levels of miRNA-182 in the miRNA-182 inhibitor transfection group were significantly decreased compared with the control groups. The expression level of miRNA-182 in the cells transfected with miRNA-182 mimic was significantly increased compared with the control groups. Experiments were repeated three times. Data are presented as the mean \pm standard deviation. ${ }^{* *} \mathrm{P}<0.01$ vs. control groups. miRNA, microRNA. 


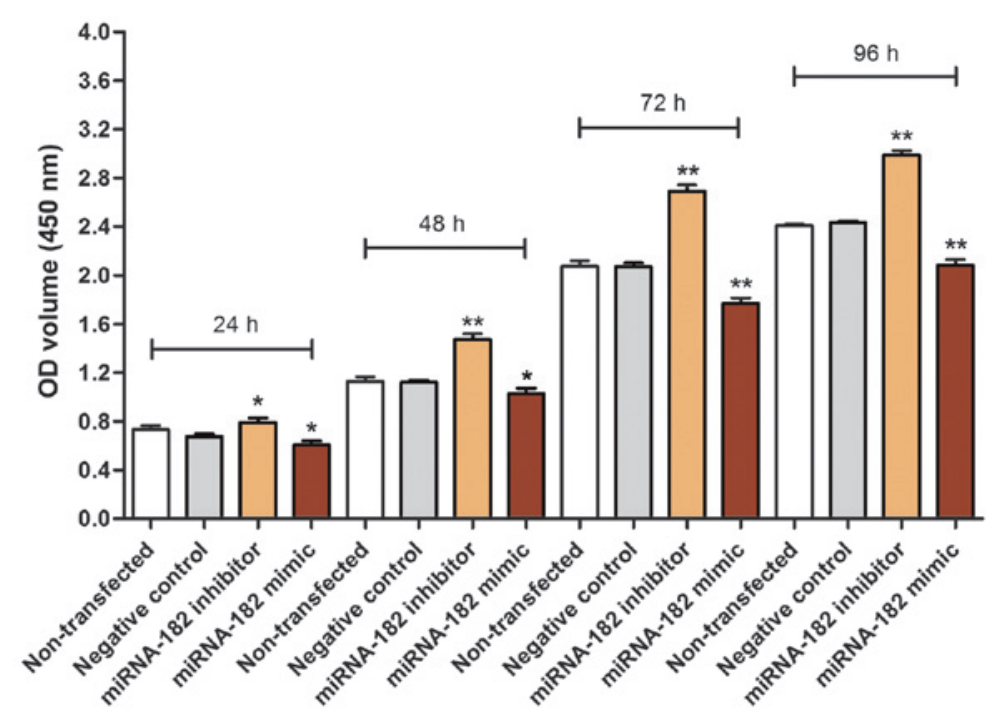

Figure 4. Cell counting kit- 8 assay OD values revealed the effects of miRNA-182 on human osteosarcoma MG-63 cell viability. The cell viability of the group transfected with miRNA-182 inhibitor was increased compared with the control groups and decreased in cells transfected with the miRNA-182 mimic. Experiments were repeated three times. Data are presented as the mean \pm standard deviation. ${ }^{*} \mathrm{P}<0.05 ;{ }^{* *} \mathrm{P}<0.01$ vs. control groups. OD, optical density; miRNA, microRNA.

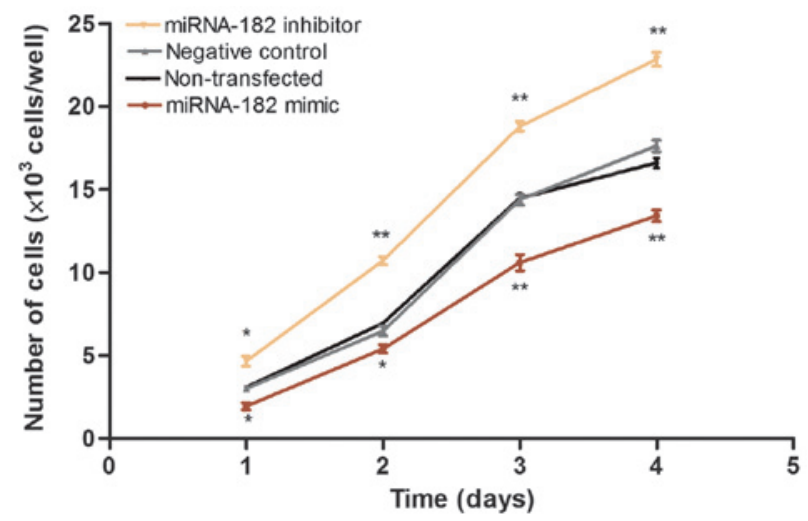

Figure 5. Cell proliferation. According to the OD values measured at various time points, a cell growth curve was plotted. Cell proliferation was increased in the cells transfected with the miRNA-182 inhibitor and decreased in cells transfected with the miRNA-182 mimic compared with the control groups. These results were statistically significant. Data are expressed as the mean \pm standard deviation from triplicates of one experiment. ${ }^{*} \mathrm{P}<0.05$, ${ }^{* * *} \mathrm{P}<0.01 \mathrm{vs}$. control groups. miRNA, microRNA.

the group transfected with miRNA-182 mimic was decreased compared with the control groups, suggesting that upregulation of miRNA-182 expression reduces MG-63 cell viability (Fig. 4). A cell proliferation curve was plotted according to the standard curve, which was obtained from OD values (Fig. 5). The results were similar to the results observed for cell viability and were statistically significant; cell proliferation was increased in cells transfected with the miRNA-182 inhibitor and decreased in cells transfected with the miRNA-182 mimic compared with the control groups.

Effects of miRNA-182 on cell apoptosis. A total of $24 \mathrm{~h}$ subsequent to transfection, Annexin V-FITC and PI were used for cell staining. The single-FITC stained cells were analyzed statistically as the ratio of early apoptotic cells. When cells were transfected with the miRNA-182 inhibitor, mimic or negative control, the percentage of apoptotic cells was $2.33 \pm 0.27,14.76 \pm 0.72$ and $5.62 \pm 0.84 \%$, respectively. Flow cytometric analysis indicated that the percentage of apoptotic cells was significantly increased in the group transfected with the miRNA-182 mimic and reduced in the group transfected with the miRNA-182 inhibitor compared with the negative control group (Fig. 6). These results suggest that upregulation of miRNA-182 expression promotes apoptosis of MG-63 cells.

Effects of miRNA-182 on cell invasion and migration. Following solidification, the number of cells passing through the Matrigel was counted following an incubation period of $24 \mathrm{~h}$ for invasive cells and $5 \mathrm{~h}$ for migrating cells. The numbers of cells in the inhibitor, mimic and negative control groups were $129 \pm 11,36 \pm 7$ and $72 \pm 10$, respectively, per visual field following $24 \mathrm{~h}$ of incubation. The number of MG-63 cells in the inhibitor group that passed through the Transwell chamber was significantly increased (Fig. 7), which suggests that transfection of the miRNA-182 inhibitor promoted cell invasiveness. Following incubation in Transwell chambers for $5 \mathrm{~h}$, the number of cells passing through the Matrigel was counted. The number of migrating cells 
A

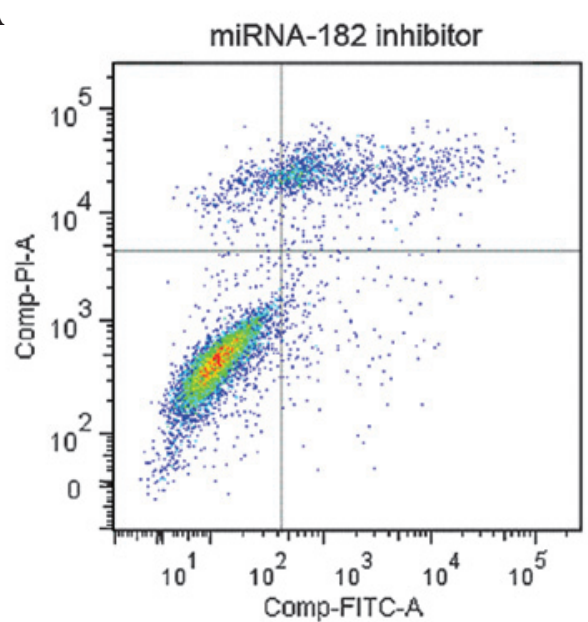

C

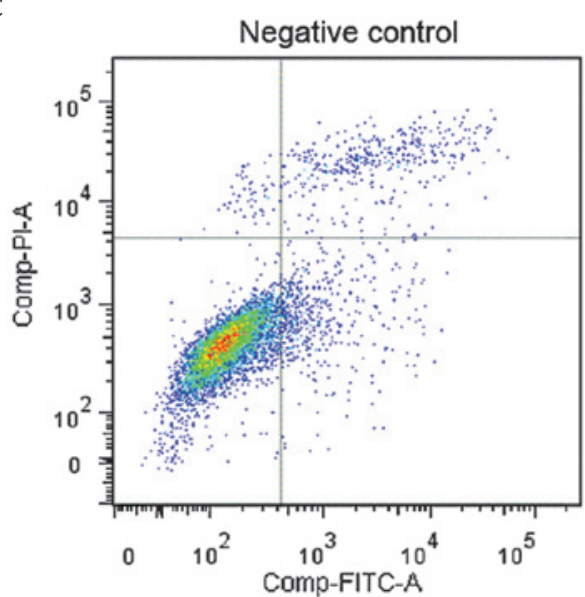

B

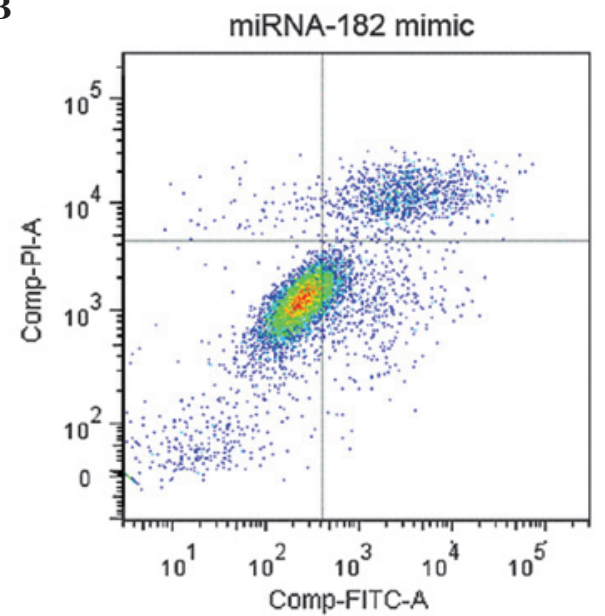

D

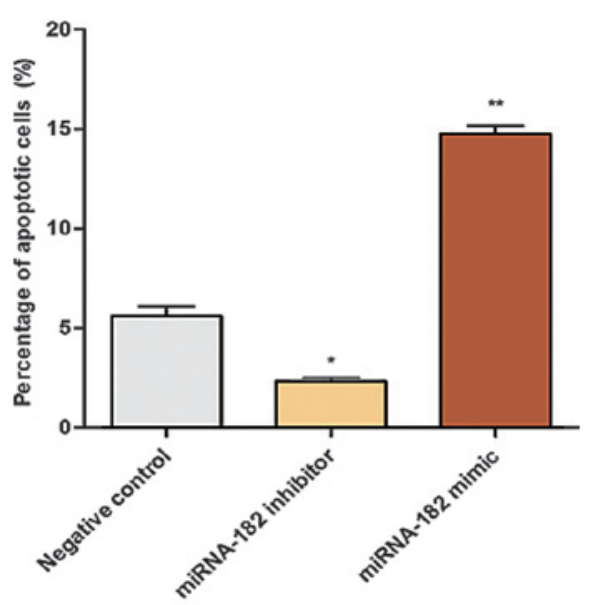

Figure 6. Flow cytometric analysis of the effects of miRNA-182 expression on cell apoptosis. Annexin V-FITC and propidium iodide were used for cell staining. The single-FITC stained cells were analyzed statistically as the ratio of early apoptotic cells. The percentage of apoptotic cells of the (A) miRNA-182 inhibitor was $2.33 \pm 0.27 \%$, (B) mimic was $14.76 \pm 0.72 \%$ and (C) negative control was $5.62 \pm 0.84 \%$. (D) The percentage of apoptotic cells was significantly increased in the group transfected with miRNA-182 mimic, and lower in the group transfected with miRNA-182 inhibitor compared with the negative control group. Data are presented as the mean \pm standard deviation of three experiments. ${ }^{*} \mathrm{P}<0.05 ;{ }^{* *} \mathrm{P}<0.01$ vs. control group. miRNA, microRNA; FITC, fluorescein isothiocyanate; PI, propidium iodide; Comp, BD FACSComp ${ }^{\mathrm{TM}}$ Software.

in the inhibitor, mimic and negative groups were $165 \pm 9$, $55 \pm 8$ and $91 \pm 7$, respectively, per visual field. The number of MG-63 cells in the inhibitor group that passed through the Transwell chamber was significantly increased (Fig. 8), revealing that inhibition of miRNA-182 expression promoted cell migration.

\section{Discussion}

One of the significant challenges in cancer research is the identification of novel molecular biomarkers (35). miRNAs regulate complex networks of gene expression, and an altered expression of miRNA genes has been associated with the development of multiple types of human cancer, including OS $(36,37)$. However, the role of miRNAs in cancer biology is not well understood. Previously, it has been observed that there is a complex association between miRNA-182 and neoplasms; upregulation of miRNA-182 has been associated with cervical cancer (38), while its significant downregulation has been reported in human uveal melanoma (39). The results of the present study revealed that miRNA-182 expression levels were decreased in OS MG-6 cells and OS tissues compared with normal osteoblast hFOB1.19 cells and are similar to the results of previous reports, which describe the association of lower levels of miRNA-182 with colon cancer and uveal melanoma $(32,39)$. In the present study, miRNA-182 is referred to as a tumor suppressor miRNA, as its functions are similar to those of tumor suppressor genes. As a tumor suppressor, miRNA-182 is important in the biological behavior of OS.

The present study revealed that an upregulation of miRNA-182 promotes cell apoptosis and inhibits cell viability, proliferation, invasion and migration. To the best of our knowledge, $>20$ articles concerning miRNA-182 have been published in various journals. The majority of these studies have demonstrated that miRNA-182 is an oncogene, and a small number of studies have confirmed that miRNA-182 is a tumor suppressor gene. Ning et al (40) confirmed that the expression level of miRNA-182 in human lung cancer A549 cells was significantly increased compared with the expression level in the human bronchial epithelial NHBE cell line. Furthermore, it was identified that an increase in programmed cell death 4 (PDCD4) protein levels occurred following transfection of a miRNA-182 inhibitor 
A

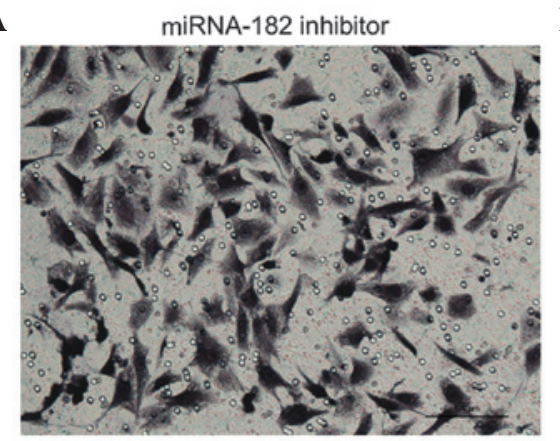

C

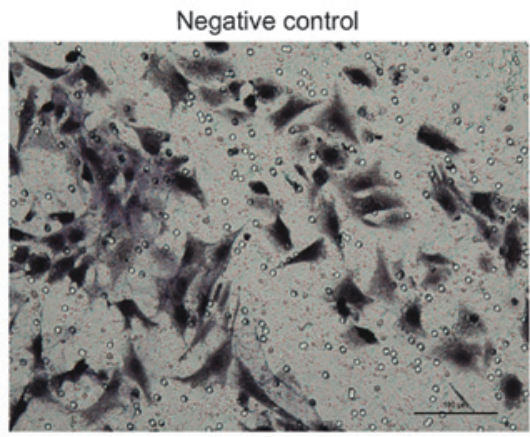

B

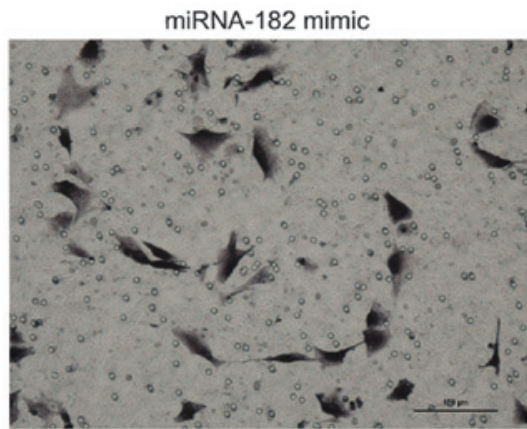

D

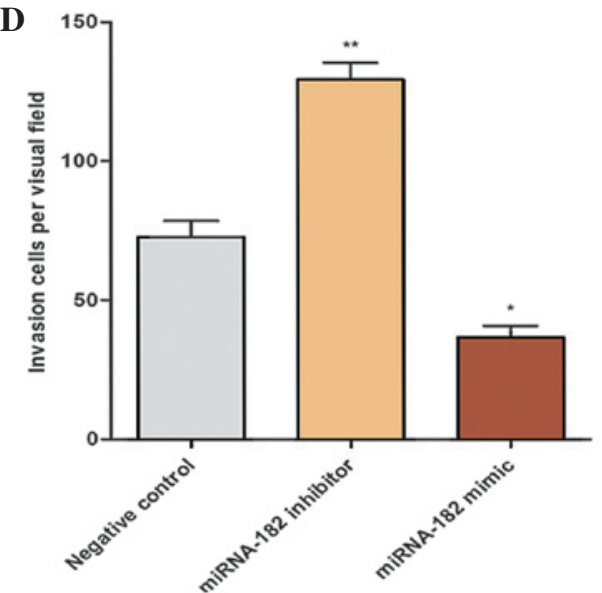

Figure 7. Results of a Transwell invasion assay analyzing the effects of miRNA-182 on cell invasion. The numbers of cells in the (A) inhibitor, (B) mimic and (C) negative control groups were $129 \pm 11,36 \pm 7$ and $72 \pm 10$, respectively, per visual field. (D) The number of MG-63 cells that passed through the Transwell chambers was significantly increased in the inhibitor group and significantly decreased in the mimic group compared with the control. Data are presented as the mean \pm standard deviation of three experiments. Magnification, $\mathrm{x} 200 .{ }^{*} \mathrm{P}<0.05,{ }^{* *} \mathrm{P}<0.01 \mathrm{vs}$. control group.

A

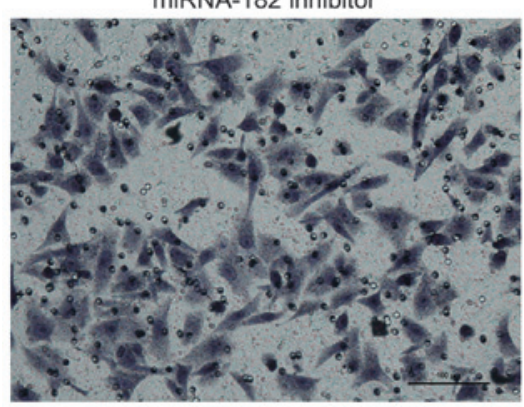

C

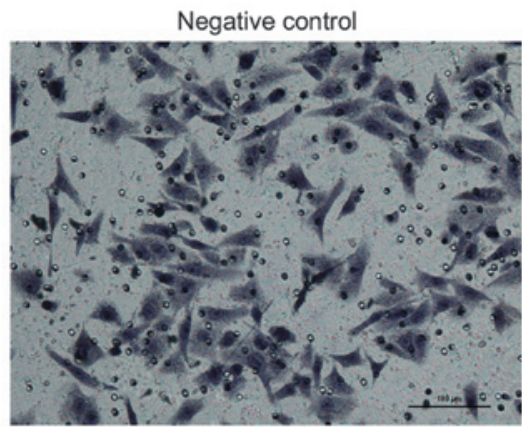

B
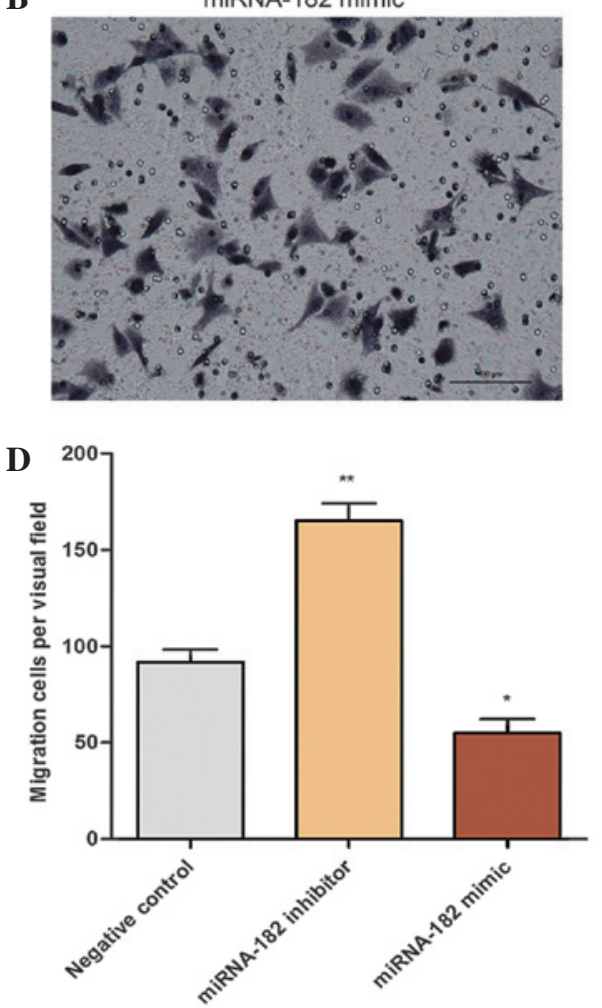

Figure 8. Results of a Transwell migration assay analyzing the effects of miRNA-182 on cell migration. The numbers of migrating cells in the (A) inhibitor, (B) mimic and (C) negative groups were 165 $\pm 9,55 \pm 8$, and 91 \pm , respectively, per visual field. (D) The number of MG-63 cells that passed through the Transwell chambers was significantly increased in the inhibitor group and significantly decreased in the mimic group. Data are presented as the mean \pm standard deviation of three experiments. Magnification, $\mathrm{x} 200 .{ }^{*} \mathrm{P}<0.05,{ }^{* *} \mathrm{P}<0.01$ vs. control group. 
using western blot analysis (40). The results from this study demonstrate that overexpression of miRNA-182 may be involved in the chemoresistance of non-small cell lung cancer cells to cisplatin by downregulating PDCD4 (40). Yang et al (41) revealed that miRNA-182 expression was increased in colorectal cancer (CRC) cells originating from metastatic foci and human primary CRC tissues with lymph node metastases. The results of this previous study illustrated that the upregulation of miRNA-182 is pivotal in CRC tumorigenesis and metastasis (41). Guo et al (42) demonstrated that miRNA-182 was significantly upregulated in an embryonal carcinoma (EC) cell line compared with nonendometrioid carcinoma. miRNA-182 serves as an oncogenic miRNA in EC as it promotes cell proliferation by targeting the tumor suppressor gene transcription elongation factor A (SII)-like 7 and modulating the activity of its downstream effectors v-myc avian myelocytomatosis viral oncogene homolog, cyclin D1 and NFkB (42). Liu et al (43) reported that miRNA-182 expression was significantly upregulated in prostate cancer tissues and four prostate cancer cell lines compared with benign prostatic hyperplasia tissues and normal prostatic epithelial RWPE-1 cells. A novel mechanism by which n-myc downstream regulated 1 is epigenetically regulated was revealed (43).

Notably, the results of Cekaite et al (32) contradicted those of Yang et al (41), and demonstrated that deregulation of miRNA-182 promoted colon cancer cell proliferation. In these previous studies, the majority of the tumors used originated from epithelial tissue. By contrast, in the current study, OS was the source of the mesenchymal tumors. The same miRNA may be expressed at various levels in tumors with various tissue origins (44-46). The majority of experimental studies focus on RNA levels and a small percentage investigate the regulation of proteins by miRNA. As regulation by miRNAs is extremely extensive, these RNAs may regulate numerous proteins in a variety of ways $(32,41)$, which resolves the former contradiction that certain studies have demonstrated that miRNA-182 is an onco-gene, and a small number of studies have confirmed that miRNA-182 is a tumor suppressor gene. miRNA-182 regulates various proteins that in turn regulate the biological behavior of tumor cells.

The results of the present study indicate that miRNA-182 is a potential tumor suppressor gene for OS, and that upregulation of miRNA-182 expression inhibits cell viability, proliferation, invasion and migration. Furthermore, miRNAs have been proposed to be used in treatment strategies that may potentially achieve improved clinical outcomes in patients with cancer. In future research, the regulatory pathways and target proteins of miRNA-182 may be determined, and studies may be performed in vivo in animal models.

\section{Acknowledgements}

The authors are grateful to the Department of Orthopedics of the First Affiliated Hospital of China Medical University (Shenyang, China).

\section{References}

1. Bramwell VH: Osteosarcomas and other cancers of bone. Curr Opin Oncol 12: 330-336, 2000
2. Kobayashi E, Hornicek FJ and Duan Z: MicroRNA involvement in osteosarcoma. Sarcoma 2012: 359739, 2012.

3. Longhi A, Errani C, De Paolis M, Mercuri M and Bacci G: Primary bone osteosarcoma in the pediatric age: State of the art. Cancer Treat Rev 32: 423-436, 2006.

4. Hartford CM, Wodowski KS, Rao BN, Khoury JD, Neel MD and Daw NC: Osteosarcoma among children aged 5 years or younger: The St. Jude children's research hospital experience. J Pediatr Hematol Oncol 28: 43-47, 2006.

5. Bielack SS, Kempf-Bielack B, Delling G, Exner GU, Flege S, Helmke K, Kotz R, Salzer-Kuntschik M, Werner M, Winkelmann W, et al: Prognosticfactors in high-grade osteosarcoma of the extremities or trunk: An analysis of 1,702 patients treated on neoadjuvant cooperative osteosarcoma study group protocols. J Clin Oncol 20: 776-790, 2002.

6. Marina N, Gebhardt M, Teot L and Gorlick R: Biology and therapeutic advances for pediatric osteosarcoma. Oncologist 9: 422-441, 2004

7. Endicott M: Principles of treatment for osteosarcoma. Clin Tech Small Anim Pract 18: 110-114, 2003.

8. Szcześniak MW, Owczarkowska E, Gapski J and Makałowska I: MicroRNA databases. Postepy Biochem 58: 91-99, 2012 (In Polish).

9. Iorio MV and Croce CM: MicroRNA involvement in human cancer. Carcinogenesis 33: 1126-1133, 2012.

10. Nikitina EG, Urazova LN and Stegny VN: MicroRNAs and human cancer. Exp Oncol 34: 2-8, 2012.

11. Bentwich I, Avniel A, Karov Y, Aharonov R, Gilad S, Barad O, Barzilai A, Einat P, Einav U, Meiri E, et al: Identification of hundreds of conserved and nonconserved human microRNAs. Nat Genet 37: 766-770, 2005.

12. Lee Y, Kim M, Han J, Yeom KH, Lee S, Baek SH and Kim VN: MicroRNA genes are transcribed by RNA polymerase II. EMBO J 23: 4051-4060, 2004.

13. Cai X, Hagedorn $\mathrm{CH}$ and Cullen BR: Human microRNAs are processed from capped, polyadenylated transcripts that can also function as mRNAs. RNA 10: 1957-1966, 2004.

14. Faller M and Guo F: MicroRNAbiogenesis: There's more than one way to skin a cat. Biochim Biophys Acta 1779: 663-667, 2008

15. Murchison EP and Hannon GJ: MiRNAson the move: MiRNA biogenesis and the RNAi machinery. Curr Opin Cell Biol 16: 223-229, 2004

16. Lund E and Dahlberg JE: Substrate selectivity of exportin 5 and Dicer in the biogenesis of microRNAs. Cold Spring Harb Symp Quant Biol 71: 59-66, 2006.

17. Bartel DP: MicroRNAs: Genomics, biogenesis, mechanism and function. Cell 116: 281-297, 2004.

18. Wang XJ, Reyes JL, Chua NH and Gaasterland T: Prediction and identification of Arabidopsis thaliana microRNAs and their mRNA targets. Genome Biol 5: R65, 2004.

19. Shukla GC, Singh J and Barik S: MicroRNAs: Processing, maturation, target recognition and regulatory functions. Mol Cell Pharmacol 3: 83-92, 2011.

20. Wang Z, Yao H, Lin S, Zhu X, Shen Z, Lu G, Poon WS, Xie D, Lin MC and Kung HF: Transcriptional and epigenetic regulation of human microRNAs. Cancer Lett 331: 1-10, 2013.

21. Rajewsky N: MicroRNA target predictions in animals. Nat Genet 38: S8-S13, 2006

22. Krek A, Grün D, Poy MN, Wolf R, Rosenberg L, Epstein EJ, MacMenamin P, da Piedade I, Gunsalus KC, Stoffel M and Rajewsky N: Combinatorial microRNA target predictions. Nat Genet 37: 495-500, 2005.

23. Jovanovic M and Hengartner MO: MiRNAs and apoptosis: RNAs to die for. Oncogene 25: 6176-6187, 2006.

24. Babar IA, Slack FJ and Weidhaas JB: MiRNA modulation of the cellular stress response. Future Oncol 4: 289-298, 2008.

25. Akçakaya P, Ekelund S, Kolosenko I, Caramuta S, Ozata DM, Xie H, Lindforss U, Olivecrona H and Lui WO: MiR-185 and miR-133b deregulation is associated with overall survival and metastasis in colorectal cancer. Int J Oncol 39: 311-318, 2011.

26. Wu H and Mo YY: Targeting miR-205 in breast cancer. Expert Opin Ther Targets 13: 1439-1448, 2009.

27. Kiselev FL: MicroRNA and cancer. Mol Biol (Mosk) 48: 232-42, 2014 (In Russian).

28. Mraz M and Pospisilova S: MicroRNAs in chronic lymphocytic leukemia: From causality to associations and back. Expert Rev Hematol 5: 579-581, 2012.

29. Calin GA, Dumitru CD, Shimizu M, et al: Frequent deletions and down-regulation of micro-RNA genes miR15 and miR16 at $13 q 14$ in chronic lymphocytic leukemia. Proc Natl Acad Sci USA 99: 15524-15529, 2002. 
30. Liu H, Wang Y, Li X, Zhang YJ, Li J, Zheng YQ, Liu M, Song X and Li XR: Expression and regulatory function of miRNA-182 in triple-negative breast cancer cells through its targeting of profilin 1. Tumour Biol 34: 1713-1722, 2013.

31. Kong WQ, Bai R, Liu T, Cai CL, Liu M, Li X and Tang H: MicroRNA-182 targets cAMP-responsive element-binding protein 1 and suppresses cell growth in human gastric adenocarcinoma. FEBS J 279: 1252-1260, 2012.

32. Cekaite L, Rantala JK, Bruun J, Guriby M, Agesen TH, Danielsen SA, Lind GE, Nesbakken A, Kallioniemi O, Lothe RA, et al: MiR-9, -31 and -182 deregulation promote proliferation and tumor cell survival in colon cancer. Neoplasia 14: 868-879, 2012.

33. Guo D, Li Q, Lv Q, Wei Q, Cao S and Gu J: MiR-27a targets sFRP1 in hFOB cells to regulate proliferation, apoptosis and differentiation. PLoS One 9: e91354, 2014.

34. Livak KJ and Schmittgen TD: Analysis of relative gene expression data using real time quantitative PCR and the 2( Delta Delta C(T)) Method. Methods 25: 402 408, 2001.

35. Duffy MJ, O'Donovan N and Crown J: Use of molecular markers for predicting therapy response in cancer patients. Cancer Treat Rev 37: 151-159, 2011.

36. Guled M and Knuutila S: MicroRNAs and cancer. Duodecim 129: 1661-1669, 2013 (In Finnish).

37. Ell B and Kang Y: MicroRNAs as regulators of bone homeostasis and bone metastasis. Bonekey Rep 3: 549, 2014.

38. Tang T, Wong HK, Gu W, Yu MY, To KF, Wang CC, Wong YF, Cheung TH, Chung TK and Choy KW: MicroRNA-182 plays an onco-miRNA role in cervical cancer. Gynecol Oncol 129: 199-208, 2013.

39. Yan D, Dong XD, Chen X, Yao S, Wang L, Wang J, Wang C, $\mathrm{Hu} \mathrm{DN}, \mathrm{Qu} \mathrm{J}$ and Tu L: Role of microRNA-182 in posterior uveal melanoma: Regulation of tumor development through MITF, BCL2 and cyclin D2. PLOS One 7: e40967, 2012.
40. Ning FL, Wang F, Li ML, Yu ZS, Hao YZ and Chen SS: MicroRNA-182 modulates chemosensitivity of human non-small cell lung cancer to cisplatin by targeting PDCD4. Diagn Pathol 9: 143, 2014.

41. Yang MH, Yu J, Jiang DM, Li WL, Wang S and Ding YQ MicroRNA-182 targets special AT-rich sequence-binding protein 2 to promote colorectal cancer proliferation and metastasis. J Transl Med 12: 109, 2014.

42. Guo Y, Liao Y, Jia C, Ren J, Wang J and Li T: MicroRNA-182 promotes tumor cell growth by targeting transcription elongation factor A-like 7 in endometrial carcinoma. Cell Physiol Biochem 32: 581-590, 2013.

43. Liu R, Li J, Teng Z, Zhang Z and Xu Y: Overexpressed microRNA- 182 promotes proliferation and invasion in prostate cancer PC-3 cells by down-regulating N-myc downstream regulated gene 1 (NDRG1). PLOS One 8: e68982, 2013.

44. Hu X, Chen D, Cui Y, Li Z and Huang J: Targeting microRNA-23a to inhibit glioma cell invasion via HOXD10. Sci Rep 3: 3423, 2013.

45. He Y, Meng C, Shao Z, Wang H and Yang S: MiR-23a functions as a tumor suppressor in osteosarcoma. Cell Physiol Biochem 34: 1485-1496, 2014.

46. Perng DW, Yang DM, Hsiao YH, Lo T, Lee OK, Wu MT, Wu YC and Lee YC: miRNA-146a expression positively regulates tumor necrosis factor- $\alpha$-induced interleukin- 8 production in mesenchymal stem cells and differentiated lung epithelial-like cells. Tissue Eng Part A 18: 2259-67, 2012. 